\title{
Defective Circulating Regulatory B Cells in Patients with Dilated Cardiomyopathy
}

\author{
Jiao Jiao Yu-Zhi Lu Ni Xia Yi-Qiu Wang Ting-Ting Tang Shao-Fang Nie \\ Bing-Jie Lv Ke-Jing Wang Shuang Wen Jing-Yong Li Xing-Di Zhou \\ Yu-Hua Liao Xiang Cheng
}

Department of cardiology, Union Hospital, Tongji Medical College, Huazhong University of Science and Technology, Wuhan, Key Lab for biological targeted therapy of Education Ministry and Hubei province, Union Hospital, Tongji Medical College, Huazhong University of Science and Technology, Wuhan, China

\section{Key Words}

Regulatory B cell (Breg) $・$ CD24hi CD27+ B cell • Dilated Cardiomyopathy (DCM)

\begin{abstract}
Background/Aims: Newly identified IL-10-producing regulatory B cells (Bregs) have been shown to play an important role in the suppression of immune responses. Chronic immune activation participates in the pathogenesis of dilated cardiomyopathy (DCM) but whether Bregs are involved in its development remains unclear. We aimed to investigate the circulating frequency and function of Bregs in DCM. Methods: In total, 35 DCM patients (20 men and 15 women) and 44 healthy controls ( 23 men and 21 women) were included in the experiment, and the frequency of Bregs was detected using flow cytometry. Results: According to our results, the frequency of circulating IL-10-producing Bregs was significantly lower in DCM patients compared with healthy controls. Furthermore, the $C D 24^{\text {hi }} C D 27^{+} B$ cell subset in which IL-10-producing Bregs were mainly enriched from DCM patients showed impaired IL-10 expression and a decreased ability to suppress the TNF- $\alpha$ production of CD4+CD25- Tconv cells and to maintain Tregs differentiation. Correlation analysis showed that the frequency of IL-10-producing Bregs and the suppressive function of $C D 24^{\text {hi }} C D 27^{+}$B cells were positively correlated with left ventricular ejection fraction and negatively correlated with NT-proBNP in DCM patients. Conclusions: In conclusion, the reduced frequency and impaired functions
\end{abstract} suggest a potential role of Bregs in the development of DCM.

\section{Introduction}

Dilated cardiomyopathy (DCM) is one of the most common causes of heart failure, which is characterized by ventricular enlargement and progressive deterioration of systolic function [1,2]. Although the pathogenesis of DCM is complicated, there is increasing

J. Jiao, Y.-Z. Lu and N. Xia contributed equally to this work. 
evidence that autoimmune disorders with cellular and humoral immune activation are involved in the development of DCM $[3,4]$. In DCM patients, T cells display enhanced expression of activation surface markers, including CD25, CD69, HLA-DR and CD40 ligand $[5,6]$. Additionally, auto-antibodies directed against heart specific-antigens were detected in their serum $[7,8]$. However, regulatory $\mathrm{T}$ cells (Tregs) have a beneficial role in DCM by suppressing TH1-dominant $\mathrm{CD}^{+}{ }^{+} \mathrm{T}$-cell responses [9-11].

B cells accelerate DCM development by secreting antibodies against cardiac proteins $[12,13]$. In addition to their functions in antibody secretion, antigen presentation and cytokine and chemokine production, B cells exhibit regulatory capacity in several human diseases, such as experimental autoimmune encephalomyelitis (EAE) [14], diabetes [15] and collagen-induced arthritis (CIA) [16]. The discrete subpopulation of B cells that has regulatory capacity is termed regulatory B cells (Bregs). Although the existence of Bregs has been well documented, there is no specific transcription factor or membrane marker to distinguish them from other B cells [17]. To date, IL-10 production has been considered a defining trait of Bregs [18]. The phenotypes of human Bregs remain controversial, and different $\mathrm{B}$ cell subsets, including $\mathrm{CD} 19^{+} \mathrm{CD} 24^{\mathrm{hi}} \mathrm{CD} 38^{\mathrm{hi}}$ and $\mathrm{CD} 19^{+} \mathrm{CD} 24^{\mathrm{hi}} \mathrm{CD} 27^{+} \mathrm{B}$ cells, produce IL-10 and exhibit regulatory functions in different diseases $[19,20]$.

Here, we prospectively studied the frequency, phenotype and regulatory functions of Bregs in DCM patients. According to our results, the frequency of IL-10-producing Bregs was decreased in DCM patients. Consistent with previous studies, IL-10-producing Bregs were mainly enriched in $\mathrm{CD} 24^{\mathrm{hi}} \mathrm{CD} 27^{+} \mathrm{B}$ cells. Furthermore, the $\mathrm{CD} 24^{\mathrm{hi}} \mathrm{CD} 27^{+} \mathrm{B}$ cell subset from DCM patients expressed less IL-10 compared to healthy controls. CD2 $24^{\text {hi }} \mathrm{CD} 27^{+} \mathrm{B}$ cells from DCM patients showed a decreased ability in suppressing TNF- $\alpha$ production of $\mathrm{CD}^{+}{ }^{+} \mathrm{CD} 25^{-}$Tconv cells and maintaining Treg differentiation. Correlation analysis suggested the frequency of Bregs and their suppressive function on TNF- $\alpha$ production were positively correlated with LVEF and negatively correlated with NT-proBNP in DCM patients. Thus, our results suggest a potential role of Bregs in the pathogenesis of human DCM.

\section{Materials and Methods}

\section{Patients}

35 DCM patients and 44 healthy controls were included in the experiments to evaluate IL-10 production and identify B cell subsets. DCM diagnosis was based on the guidelines of the World Health Organization (WHO) [21]. Left ventricular enlargement with LVEDD > $5.5 \mathrm{~cm}$ and LVEF $<45 \%$, which were estimated by echocardiography, were the inclusion criteria for DCM. Exclusion criteria included hypertensive heart disease, valvular heart disease, coronary heart disease, diabetes, other autoimmune diseases, serious infection, pregnancy, endocrine disease, tumors, or receiving immunosuppressive agents. The investigation conforms to the principles outlined in the Declaration of Helsinki (2013) of the World Medical Association, and the trial was approved by the Ethics Committee of Tongji Medical College of Huazhong University of Science and Technology. Patients and healthy controls were all Chinese Han population and recruited after obtaining written, informed consent.

\section{Sample preparation and cell isolation}

Blood samples were obtained after permission was received. After centrifugation, serum was collected, aliquoted, and frozen at $-80^{\circ} \mathrm{C}$ for NT-proBNP measurements. PBMCs were separated by Ficoll density gradient centrifugation and quantified by hemocytometer before subsequent use.

CD19+ ${ }^{+}$cells were isolated from PBMCs by magnetic bead purification (Miltenyi Biotec, BergischGladbach, Germany) followed by staining with the fluorescence surface marker anti-human CD24-FITC (BioLegend, San Diego, CA, USA) and anti-human CD27-Percp-Cy5.5 (BioLegend, San Diego, CA, USA) for $30 \mathrm{~min}$ at $4^{\circ} \mathrm{C}$. Subsequently, the $\mathrm{CD} 24^{\mathrm{hi}} \mathrm{CD} 27^{+} \mathrm{B}$ cells were obtained by fluorescence-activated cell sorting using the FACSAria cell-sorting system (BD Biosciences, San Jose, CA, USA). The purity of CD2 $4^{\text {hi }} \mathrm{CD} 27^{+}$B cells was $>95 \%$.

\section{KARGER}




\section{Cellular Physiology Cell Physiol Biochem 2018;46:23-35

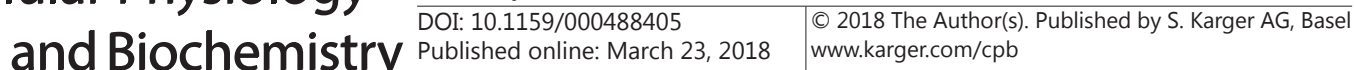

Jiao et al.: Regulatory B Cells in Dilated Cardiomyopathy

CD4 ${ }^{+}$CD25- Tconv cells were isolated by magnetic bead purification (Miltenyi Biotec, BergischGladbach, Germany). The purity of CD4+CD25-Tconv cells was > 95\%.

\section{Flow cytometry analysis}

To characterize IL-10+ B cells, PBMCs were stimulated with CpG-ODN 2006 (2.5 ug/ml; Invitrogen, Carlsbad, CA, USA) and CD40L ( $1 \mathrm{ug} / \mathrm{ml}$; R\&D Systems, Minneapolis, MN, USA) for 48 hours, and PMA (50 ng/ml; Sigma-Aldrich, St. Louis, MO, USA), ionomycin (250 ng/ml; Sigma-Aldrich, St. Louis, MO, USA) and brefeldin A ( $1 \mathrm{ul} /$ test; BD Biosciences, San Jose, CA, USA) were added for the last 5 hours. Surface marker anti-human CD19-APC, CD24-FITC, CD27-PerCP/Cy5.5 and CD38-PE/Cy7 mAbs were stained at $4^{\circ} \mathrm{C}$ for 30 min, and then the cells were fixed, permeabilized and stained to detect intracellular cytokines with an antihuman IL-10-PE mAb.

In a co-culture system, anti-human CD4-FITC, CD25-PE, and CD127-PE/Cy7 mAbs were used to identify Tregs. To evaluate the cytokine production of Tconv cells, anti-human TNF- $\alpha$-APC combined with CD4-FITC were used in the staining method described above.

All of the fluorescent antibodies described above were purchased from BioLegend (San Diego, CA, USA). Isotype controls were used for background correction and to confirm antibody specificity. Stained cells were analyzed with a FACSCalibur flow cytometer (BD Biosciences, San Jose, CA, USA).

T cell proliferation and suppression assays

For the T cell proliferation and suppression assays, $\mathrm{CD} 4{ }^{+} \mathrm{CD} 25^{-}$Tconv cells were cultured either alone or $1: 1$ with sorted $\mathrm{CD} 24^{\mathrm{hi}} \mathrm{CD} 27^{+} \mathrm{B}$ cells. Cells were resuspended at a concentration of $10^{5}$ per $100 \mu \mathrm{l}$ and cultured in a final volume of $200 \mu \mathrm{l}$ in U-bottom 96-well plates. Cells were incubated in RPMI-1640 medium (Gibco, Life Technologies, Grand Island, NY, USA) with 10\% heat-inactivated FCS (Gibco, Life Technologies, Grand Island, NY, USA), $100 \mathrm{U} / \mathrm{ml}$ penicillin, $100 \mathrm{U} / \mathrm{ml}$ streptomycin, $25 \mathrm{mM}$ HEPES, and $2 \mathrm{mM}$ L-glutamine at $37^{\circ} \mathrm{C}$.

To detect the TNF- $\alpha$ production of $\mathrm{CD}^{+} \mathrm{CD} 25^{-}$Tconv cells, the cells were stimulated with plate-bound anti-CD3 (1 ug/ml; eBioscience, San Diego, CA, USA) and soluble anti-CD28 (1 ug/ml; eBioscience, San Diego, CA, USA) for 3 days. PMA (50 ng/ml; Sigma-Aldrich, St. Louis., MO, USA), ionomycin (250 ng/ml; Sigma-Aldrich, St. Louis, MO, USA), and brefeldin A (1 ul/test; BD Biosciences, San Jose, CA, USA) were added for the last 5 hours of culture. The supernatants were collected for ELISA (R\&D Systems, Minneapolis, MN, USA) detection, and the cells were harvested for flow cytometry (BD Biosciences, San Jose, CA, USA) analysis.

For the proliferation assay, CD4 ${ }^{+} \mathrm{CD} 25^{-}$Tconv cells were stained with CFSE $(1 \mathrm{uM}$; eBioscience, San Diego, CA, USA) ahead of the culture. The staining procedure of CFSE was performed according to the manufacturer's instructions. After, the cells were cultured in the presence of plate-bound anti-CD3 (1 ug/ $\mathrm{ml}$; eBioscience, San Diego, CA, USA) and soluble anti-CD28 (1 ug/ml; eBioscience, San Diego, CA, USA) for 4 days. After being harvested, the CFSE of CD4+CD25- Tconv cells was analyzed by flow cytometry (BD Biosciences, San Jose, CA, USA) to evaluate their proliferation.

To explore the capacity of $\mathrm{CD} 24^{\text {hi }} \mathrm{CD} 27^{+} \mathrm{B}$ cells to maintain Tregs, the cells were cultured in the presence of plate-bound anti-CD3 (0.5 ug/ml; eBioscience, San Diego, CA, USA). After 3 days of culture, the cells were collected and assayed by flow cytometry (BD Biosciences, San Jose, CA, USA).

\section{Electrochemiluminescence immunoassay of serum NT-proBNP}

Roche Elecsys Electrochemiluminescence Immunoassay (Roche Diagnostics, Indianapolis, IN, USA) was used to detect serum NT-proBNP, and the protocol was performed according to the manufacturer's instructions.

\section{Statistical analysis}

All values are expressed as the mean \pm SEM. The significance was evaluated by unpaired $t$-test or oneway ANOVA with Bonferroni adjustment as specified. Spearman's correlation analysis was performed to calculate the correlation coefficients and their significance. $P<0.05$ or a confidence interval of $95 \%$ was considered significant. SPSS 17.0 software was used for the analyses. 


\section{Results}

\section{Basic Patient Characteristics}

The basic characteristics of healthy controls and DCM patients are presented in Table 1. Compared to healthy controls, patients with DCM showed a significant reduced left ventricular ejection fraction (LVEF), enlarged left ventricular enddiastolic dimension (LVEDD) and elevated NT-proBNP concentration. There were no differences in gender and age between the 2 groups.

The proportion of Bregs was decreased in patients with DCM

Bregs have no specific surface marker or transcription factor, and IL-10 production is considered their defining characteristic. To compare the circulating frequency of Bregs, we collected peripheral blood of 35 DCM patients and 44 healthy controls. After stimulation with CD40L and CpG for $48 \mathrm{~h}, \mathrm{PBMCs}$ were used for intracellular IL-10 staining. The proportions of $\mathrm{CD}^{2} 9^{+} \mathrm{B}$ cells were $8.12 \%$ $\pm 0.55 \%$ in healthy controls and $6.88 \pm$ $0.51 \%$ in DCM patients, and the difference was not significant $(P=0.10)$. However, patients with DCM were associated with a significant impairment in the frequency of Bregs $(P<0.01)$ compared to healthy controls (Fig. 1).
Table 1. Clinical characteristics of the study population. The data shown in Table 1 . are presented as percentages, numbers or mean \pm SD. NYHA indicates New York Heart Association; ACEI, angiotensin-converting enzyme inhibitor; ARB, angiotensin receptor blocker. ${ }^{\text {a }}$ $\mathrm{P}<0.01$ versus control group. ${ }^{\mathrm{b}} \mathrm{P}<0.05$ versus control group

\begin{tabular}{lcc}
\hline Characteristics & DCM group (n=35) & Control group (n=44) \\
\hline Age (years) & $54 \pm 15$ & $52 \pm 15$ \\
Sex (male/female) & $20 / 15$ & $23 / 21$ \\
NYHA (II/III/IV) & $9 / 16 / 10$ & - \\
LVEF (\%) & $32.9 \pm 9.9^{\text {a }}$ & $65.4 \pm 5.5$ \\
LVEDD (cm) & $6.5 \pm 0.8^{\text {a }}$ & $4.4 \pm 0.4$ \\
Hypertension (n, \%) & $5,14.3 \%{ }^{\mathrm{b}}$ & $2,4.5 \%$ \\
Diabetes (n, \%) & $0,0 \%$ & $0,0 \%$ \\
NT-proBNP (pg/ml) & $4063 \pm 1587^{\text {a }}$ & $72.4 \pm 11.0$ \\
Medication (n, \%) & & \\
ACEI/ARBs & $23(65.7 \%)^{\text {a }}$ & $2(4,5 \%)$ \\
Digitalis & $10(28.6 \%)^{\text {a }}$ & $0(0 \%)$ \\
$\beta$-Blocker & $18(51.4 \%)^{\text {a }}$ & $2(4,5 \%)$ \\
Diuretics & $30(85.7 \%)^{\text {a }}$ & $0(0 \%)$ \\
\hline
\end{tabular}

Fig. 1. The frequency of Regulatory B cells (Bregs) was decreased in DCM patients. Peripheral blood monocular cells (PBMCs) isolated from dilated cardiomyopathy (DCM) patients or healthy controls were cultured in the presence of CD40L and CpG-ODN2006. After 48 hours, the cells were harvested and stained for the expression of CD19 and IL-10. (A) Representative flow cytometry dot plots of one control and one DCM patient. IL-10 expression is shown on the gate of $\mathrm{CD} 19^{+} \mathrm{B}$ cells. (B) Scatter plots show mean percentages of

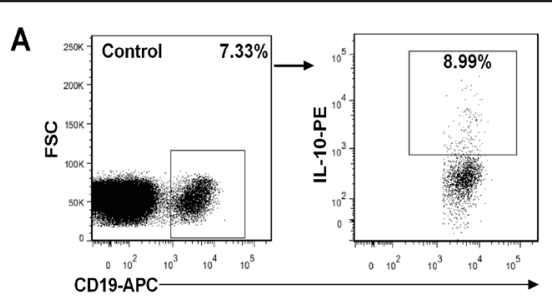

B
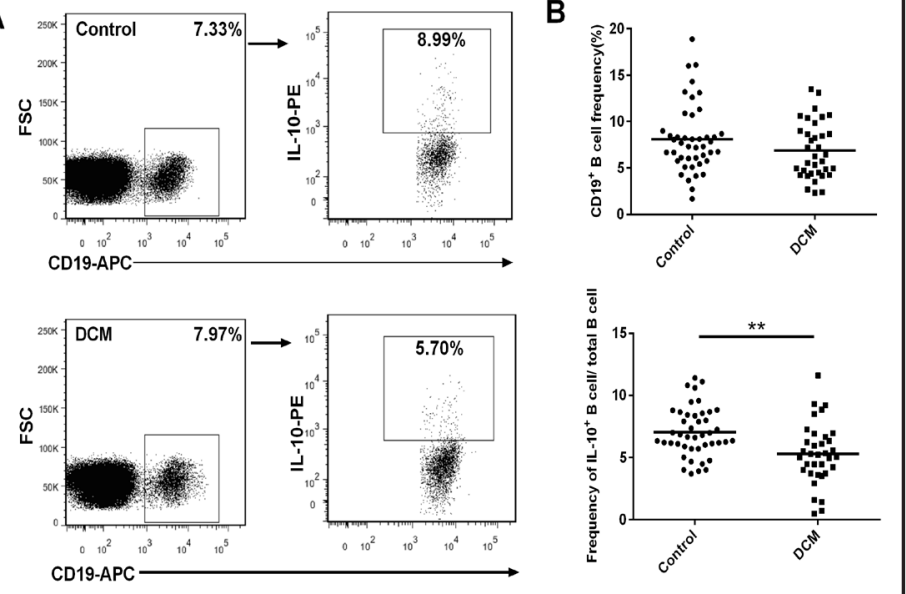
CD19 ${ }^{+}$B cells and IL-10 expression. Thirty-five patients and 44 controls were included in this experiment. $* * \mathrm{P}<0.01$. 
A
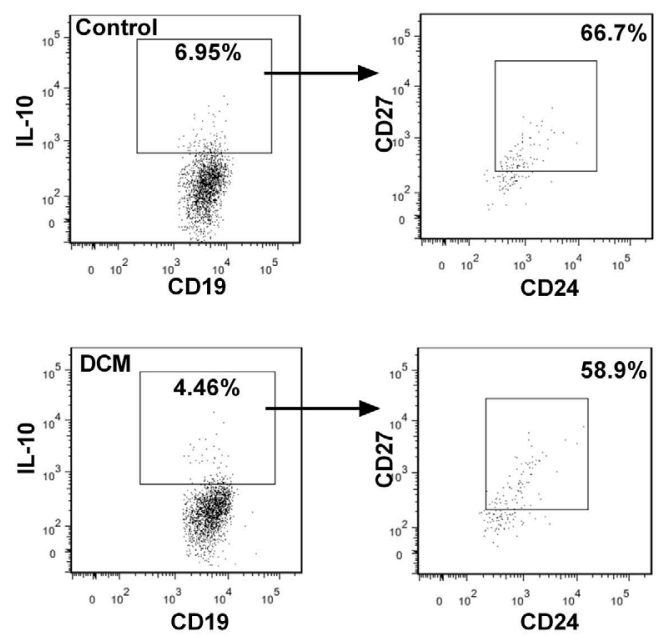

C
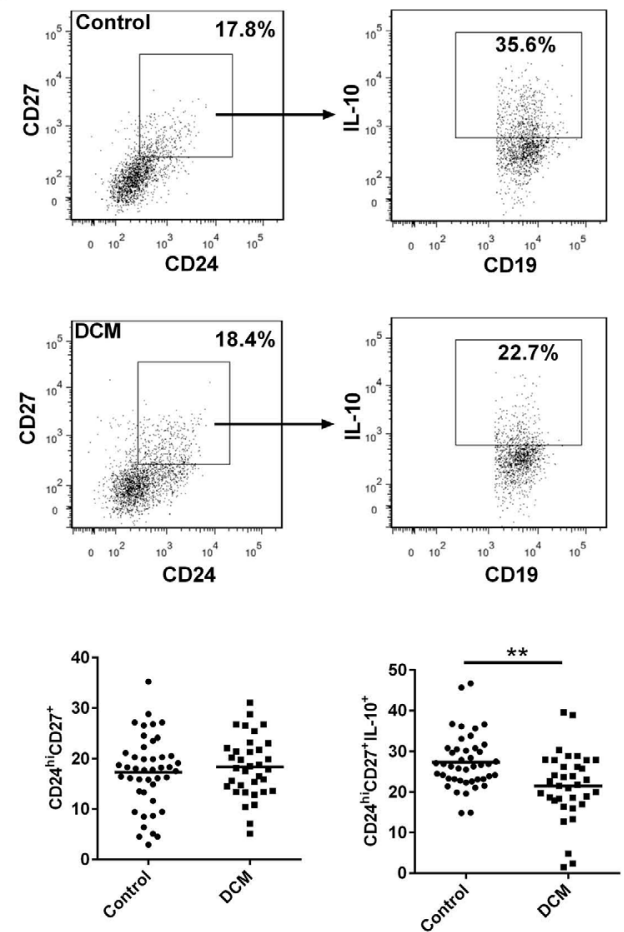

D
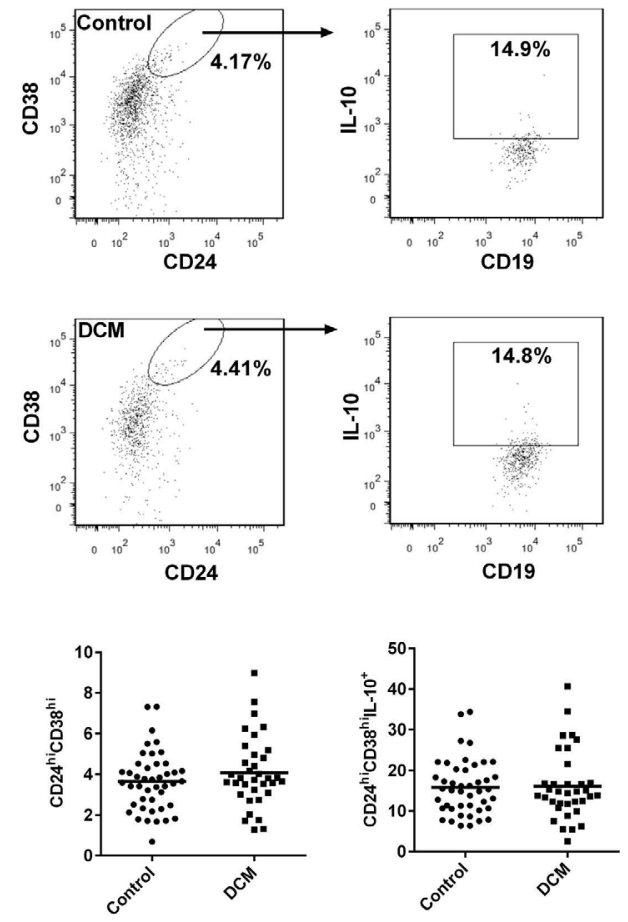

Fig. 2. IL-10 expression of $\mathrm{CD} 24^{\mathrm{hi}} \mathrm{CD} 27^{+} \mathrm{B}$ cells was lower in DCM patients. PBMCs isolated from DCM patients and healthy controls were stimulated with CD40 and CpG-0DN2006 for 48 hours. After culture, we collected cells and stained for CD19, CD38, CD24, CD27 and IL-10. (A) Representative flow cytometry dot plots of one control and one DCM patient. IL-10 expression is shown on the gate of CD19+B cells, and CD24, CD27 expression is shown on the gate of CD19+ $\mathrm{IL}-10^{+}$Bregs. (B) Scatter plots show the mean frequency of CD19+IL-10+ Bregs in CD24 ${ }^{\text {hi }} \mathrm{CD} 27^{+}$B cells. (C) Representative flow cytometry dot plots of one healthy control and one DCM patient. CD24, CD27 expression is shown on the gate of CD19+ B cells, and IL-10 expression is shown on the gate of $\mathrm{CD} 24^{\text {hi }} \mathrm{CD} 27^{+}$Bregs. Scatter plots show mean percentages of CD24 ${ }^{\text {hi }} \mathrm{CD} 27^{+}$ cells and IL-10 expression. (D) Representative flow cytometry dot plots of one control and one DCM patient. $\mathrm{CD} 24$, CD38 expression is shown on the gate of $\mathrm{CD} 19^{+} \mathrm{B}$ cells, and IL-10 expression is shown on the gate of a CD24 ${ }^{\text {hi }} C D 38^{\text {hi }} B$ cell subset. Scatter plots show mean percentages of a CD2 $4^{\text {hi }} C D 38^{\text {hi }} B$ cell subset and IL-10 expression. 35 patients and 44 controls were included in this experiment. ${ }^{* *} \mathrm{P}<0.01$. 


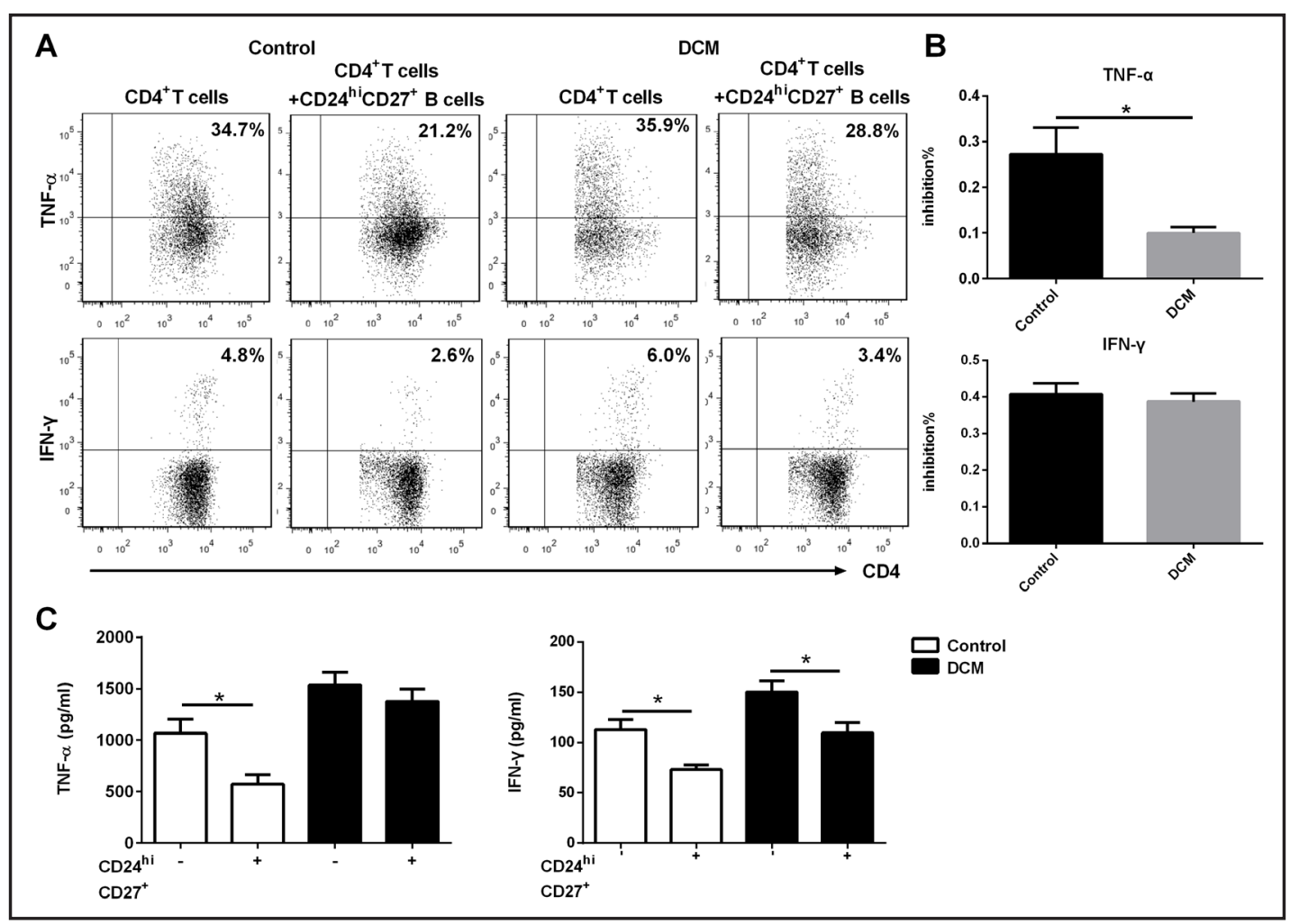

Fig. 3. $\mathrm{CD} 24^{\mathrm{hi}} \mathrm{CD} 27^{+} \mathrm{B}$ cells in DCM patients are functionally impaired in suppressing tumor necrosis factor $-\alpha\left(\right.$ TNF- $\alpha$ ) production. PBMCs were isolated from DCM patients and healthy controls. CD4 ${ }^{+}$CD25- Tconv cells were separated by magnetic beads, and $\mathrm{CD} 24^{\mathrm{hi}} \mathrm{CD} 27^{+}$Bregs were purified by fluorescence activated cell sorting (FACS). Bregs were co-cultured with Tconv cells at a 1:1 ratio. Co-cultured cells were stimulated with plate-bound anti-CD3 and soluble anti-CD28 for $72 \mathrm{~h}$. Thereafter, the cells were harvested for CD4, TNF- $\alpha$ and IFN- $\gamma$ staining while culture supernatants were collected to detect the cytokines. The concentration of TNF- $\alpha$ and IFN- $\gamma$ in the supernatant were detected by enzyme-linked immuno sorbent assay (ELISA). (A) Representative flow cytometry dot plots of one healthy control and one DCM patient. TNF- $\alpha$ and IFN- $\gamma$ expression are shown on the gate of $\mathrm{CD}^{+}{ }^{+} \mathrm{T}$ cells. (B) The bar graph shows the mean \pm SEM percentage inhibition of TNF- $\alpha$ and IFN- $\gamma$ expression by CD4 ${ }^{+}$T cells after culture. (C) The bar graph shows the mean \pm SEM concentration of TNF- $\alpha$ and IFN- $\gamma$ in the culture supernatants. 17 patients and 15 controls were included in this experiment.

\section{IL-10 expression in $C D 24^{\text {hi }} C D 27^{+}$B cells was significantly lower in DCM patients}

$\mathrm{CD} 24^{\text {hi }} \mathrm{CD} 27^{+}$and $\mathrm{CD} 24^{\mathrm{hi}} \mathrm{CD} 38^{\text {hi }} \mathrm{B}$ cells are most reported Bregs which express IL-10 and reveal regulatory functions in human autoimmune disease [22-25]. To determine in which commonly recognized B cell subsets Bregs from DCM patients were enriched, we stained the PBMCs with CD19, CD24, CD38 and CD27. Consistent with previous studies, IL-10-producing Bregs were mainly within the $\mathrm{CD} 24^{\mathrm{hi}} \mathrm{CD} 27^{+} \mathrm{B}$ cells in both groups. The proportion of IL-10producing Bregs in $\mathrm{CD} 24^{\mathrm{hi}} \mathrm{CD} 27^{+} \mathrm{B}$ cells were $66.29 \% \pm 1.87 \%$ in patients and $66.95 \% \pm$ $1.45 \%$ in controls (Fig. 2A and 2B), which indicated that there is no significant difference between the 2 groups $(P=0.78)$. Moreover, IL-10-producing Bregs possessed comparable proportions in $\mathrm{CD} 24^{\text {hi }} \mathrm{CD} 38^{\text {hi }} \mathrm{B}$ cells and $\mathrm{CD} 24^{\text {int }} \mathrm{CD} 38^{\text {int }} \mathrm{B}$ cells between DCM patients and healthy controls (data not shown).

To determine which subset was responsible for the decreasing frequency of IL-10producing Bregs, we investigated IL-10 expression of both B cell subsets in healthy controls and DCM patients. We were surprised to find that IL-10 expression of CD24 ${ }^{\text {hi }} \mathrm{CD} 27^{+} \mathrm{B}$ in DCM patients was significantly lower than in healthy donors $(21.54 \% \pm 1.42 \%$ vs. $27.36 \% \pm 1.00 \%$, 
$P<0.01)$. In contrast, the proportions of IL- $10^{+}$cells in CD24hi $\mathrm{CD} 38^{\text {hi }} \mathrm{B}$ cells were comparable in both groups (Fig. 2C and 2D). The data suggested impaired regulatory functions of $\mathrm{CD} 24^{\mathrm{hi}} \mathrm{CD} 27^{+} \mathrm{B}$ cells in DCM patients. In addition, there was no significant difference in the ratios of $\mathrm{CD} 24^{\mathrm{hi}} \mathrm{CD} 38^{\mathrm{hi}} \mathrm{B}$ cells and $\mathrm{CD} 24^{\mathrm{hi}} \mathrm{CD} 27^{+} \mathrm{B}$ cells between healthy controls and DCM patients (Fig. 2C and 2D).

$C D 24^{\text {hi } C D 27^{+}}$B cells in DCM patients are functionally impaired in suppressing TNF- $\alpha$ production

To gain further insight into the regulatory function of $\mathrm{CD} 24^{\text {hi }} \mathrm{CD} 27^{+} \mathrm{B}$ cells, we sorted a purified $\mathrm{CD} 24^{\mathrm{hi}} \mathrm{CD} 27^{+} \mathrm{B}$ cell subset and evaluated their effects on the TNF- $\alpha$ and IFN- $\gamma$ production of $\mathrm{CD} 4^{+} \mathrm{CD} 25^{-}$Tconv cells through co-culture. After stimulation with plate-bound anti-CD3 and soluble anti-CD28 for 3 days, the supernatant was collected and the cytokines were detected by ELISA. Subsequently, the cultured cells were stained with CD4, TNF- $\alpha$ and IFN $-\gamma$ successively and analyzed by flow cytometry. Consistent with previous studies, cultured $\mathrm{CD}^{+} \mathrm{CD} 25^{-}$Tconv cells from DCM patients showed a higher expression level of TNF-a and IFN- $\gamma$ compared to healthy controls. Of note, the CD $24^{\text {hi }} \mathrm{CD} 27^{+} \mathrm{B}$ cells from patients exhibited an impaired capacity to suppress the TNF- $\alpha$ production of Tconv cells. However, $\mathrm{CD} 24^{\text {hi }} \mathrm{CD} 27^{+} \mathrm{B}$ cells from both groups suppressed IFN- $\gamma$ production by T cells, but there is no significant difference of inhibition ability between DCM patients and Healthy controls, which means the inhibition ability of $\mathrm{CD} 24^{\mathrm{hi}} \mathrm{CD} 27^{+} \mathrm{B}$ cells from DCM patients in IFN- $\gamma$ production by $\mathrm{T}$ cells is not impaired (Fig. 3).

CD24 ${ }^{\text {hi } C D 27^{+}}$B cells in DCM patients showed unimpaired ability to inhibit Tconv proliferation

To further determine the suppressive function of $\mathrm{CD} 24^{\text {hi }} \mathrm{CD} 27^{+} \mathrm{B}$ cells on the proliferation of Tconv cells, purified CD2 $4^{\text {hi }} \mathrm{CD} 27^{+}$B cells from either healthy controls or DCM patients were co-cultured with CFSE-stained $\mathrm{CD} 4^{+} \mathrm{CD} 25^{-}$Tconv at a 1:1 ratio and stimulated with platebound anti-CD3. The proliferation of Tconv cells was detected by flow cytometry after 4 days

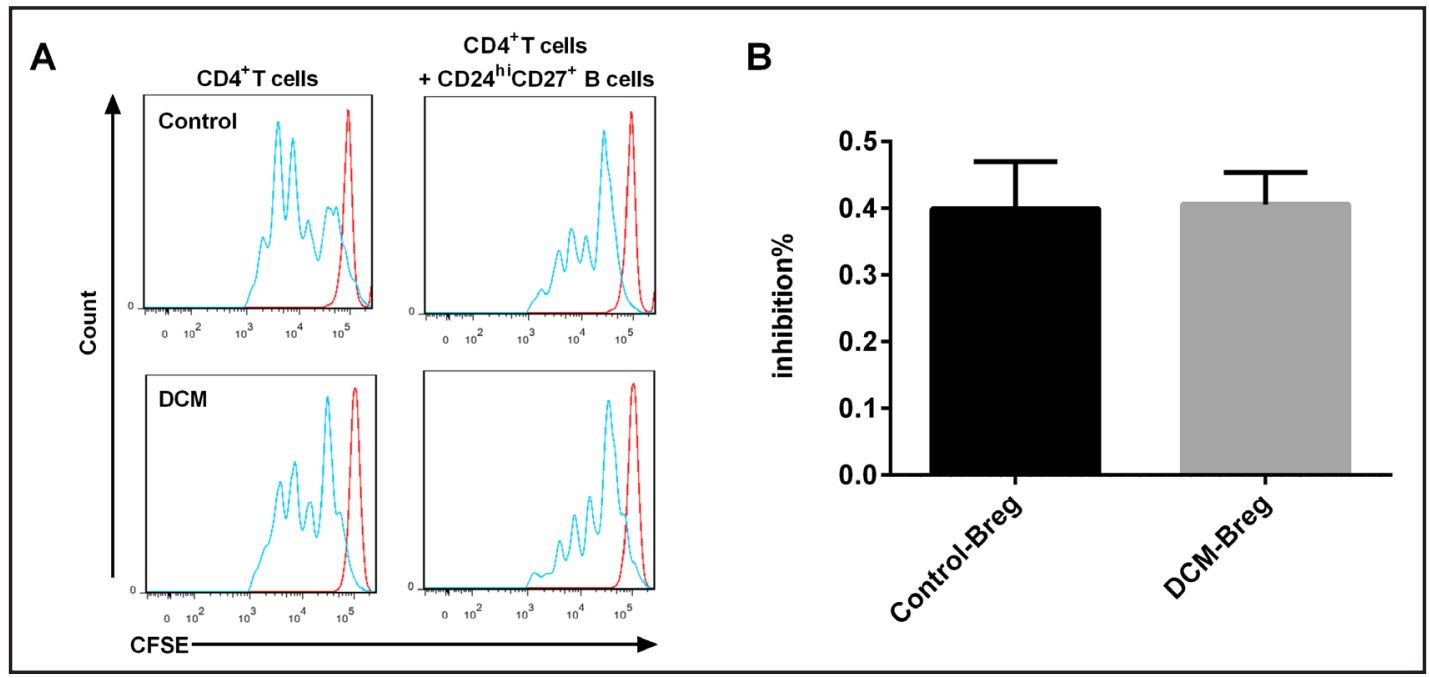

Fig. 4. $C D 24^{\text {hi }} C D 27^{+} B$ cells in DCM patients showed unimpaired ability to inhibit Tconv proliferation. PBMCs were isolated from DCM patients and healthy controls. CD4+CD25- Tconv cells were separated by magnetic beads, and CD24 ${ }^{\text {hi }} \mathrm{CD} 27^{+}$Bregs were purified by fluorescence activated cell sorting (FACS). Bregs were co-cultured with Tconv cells at a 1:1 ratio. For proliferation assay, co-cultured cells were stimulated with plate-bound anti-CD3 for $96 \mathrm{~h}$. (A) Representative flow cytometry proliferation images of one healthy control and one DCM patient. CFSE is shown on the gate of CD4+ T cells. (B) The bar graph shows the mean \pm SEM percentage inhibition of Tconv cells by $C D 4^{+} \mathrm{T}$ cells after culture. 9 patients and 10 control were included in this experiment. 
of co-culture. According to our result, Bregs from both groups showed almost the same ability to inhibit Tconv cell proliferation (Fig. 4)

The ability of
CD24 2 CD27
in DCM cells
to maintain $\quad$ Tregs
differentiation is
significantly decreased
Tregs, which play a
vital role in maintaining self-tolerance, were decreased and functioned defectively in patients with DCM [26]. Until now, it has been unknown whether the impairment of Tregs in DCM is attributed to other cell populations. As Bregs have been shown to maintain Treg differentiation [27], we next aimed to assess the ability of $\mathrm{CD} 24^{\mathrm{hi}} \mathrm{CD} 27^{+}$ $\mathrm{B}$ cells to promote Treg differentiation in DCM patients. $\quad \mathrm{CD} 24^{\mathrm{hi}} \mathrm{CD} 27^{+} \mathrm{B}$ cells were sorted and cocultured with Tconv cells in the presence of plate-bound anti-CD3 for 3 days. To detect the proportion of Tregs $\left(\mathrm{CD} 4{ }^{+} \mathrm{CD} 25^{\text {high }} \mathrm{CD} 127^{\text {low }}\right.$ ), the cultured cells were then stained with CD4, CD25 and CD127. $\mathrm{CD} 24^{\mathrm{hi}} \mathrm{CD} 27^{+}$ $B$ cells promoted more

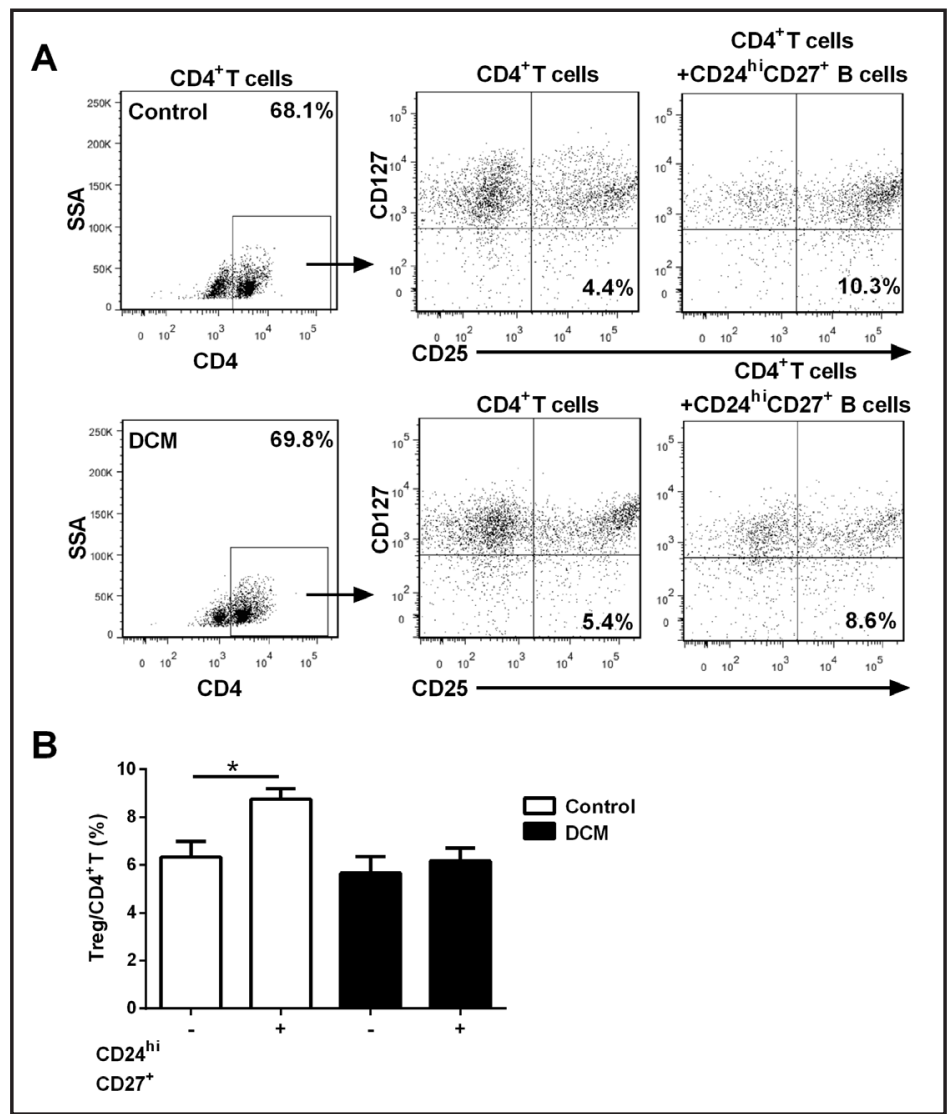

Fig. 5. $C D 24^{\text {hi }} C D 27^{+} B$ cells from DCM patients failed to promote Treg differentiation. PBMCs were isolated from DCM patients and healthy controls. CD $4^{+} \mathrm{CD} 25^{-}$Tconv cells were separated by magnetic beads, and $\mathrm{CD} 24^{\mathrm{hi}} \mathrm{CD} 27^{+}$B cells were purified by FACS. CD $24^{\mathrm{hi}} \mathrm{CD} 27^{+} \mathrm{B}$ cells were co-cultured with Tconv cells at a 1:1 ratio. Co-cultured cells were stimulated with plate-bound anti-CD3 for $72 \mathrm{~h}$. CD4, CD25 and CD127 were stained to identify Treg differentiation. (A) Representative flow cytometry proliferation images of one control volunteer and one DCM patient. CD25 and CD127 expression is shown on the gate of CD4 $4^{+}$ cells. (B) The bar graph shows the mean \pm SEM percentage of Tregs in $\mathrm{CD}^{+} \mathrm{T}$ cells. 10 patients and 10 controls were included in this experiment.* $\mathrm{P}<0.05$. differentiation of Tregs in healthy controls whereas the effect was decreased in DCM patients (Fig. 5).

\section{Bregs correlated with cardiac function in DCM patients}

To discover the relationship between Bregs and cardiac function, we performed a correlation analysis. Our results showed that the frequency of IL-10-producing Bregs and the suppressive function of $\mathrm{CD} 24^{\mathrm{hi}} \mathrm{CD} 27^{+} \mathrm{B}$ cells on TNF- $\alpha$ production of Tconv cells were positively correlated with LVEF while they were negatively correlated with NT-proBNP in DCM patients (Fig. 6). The data suggested that defective Bregs in DCM was correlated with the severity of heart failure. 
Fig. 6. Correlation analysis of Bregs and indexes of cardiac function in DCM patients. The proportion of IL10-producing Bregs in total B cells was positively correlated with left ventricular ejection fraction (LVEF) $(\mathrm{A}, \mathrm{r}=0.394, \mathrm{P}<0.05, \mathrm{~N}=35)$ and negatively correlated with $\mathrm{N}$-terminal $\mathrm{B}$ type natriuretic peptide (NT-proBNP) (B, $r=-0.369, \mathrm{P}<0.05, \mathrm{~N}=35$ ); The suppressive function of $\mathrm{CD} 24^{\mathrm{hi}} \mathrm{CD} 27^{+}$ $B$ cells on pro-inflammatory cytokine TNF- $\alpha$ production of CD4+CD25Tconv cells was positively correlated with LVEF (C, $\mathrm{r}=0.581, \mathrm{P}<0.05, \mathrm{~N}=$ 17) and negatively correlated with NT-proBNP (D, $\mathrm{r}=-0.591, \mathrm{P}<0.05, \mathrm{~N}$ $=17)$.

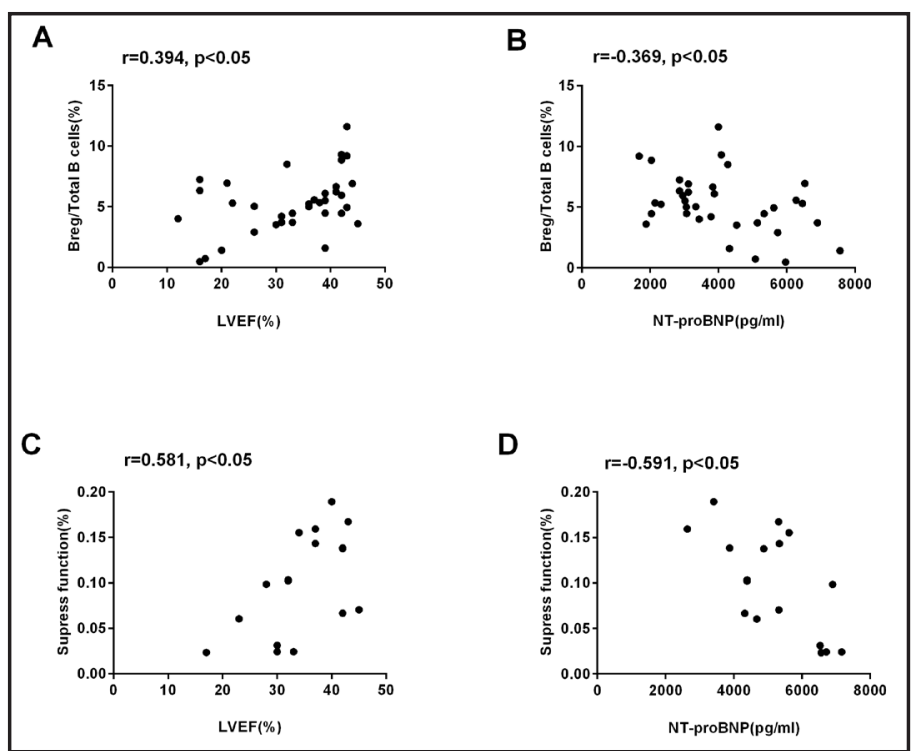

\section{Discussion}

The immune system is activated during the progress of DCM $[3,4]$. Previously, Tregs were thought to be the vital suppressor to maintain homeostasis. However, a newly identified B cell subpopulation called Bregs were shown to inhibit inflammation [28]. There is no specific surface marker or transcription factor of Bregs, and IL-10 production is considered to be the sole identification trait [17]. During the last decade, human Bregs were studied by many research groups and confirmed to be dysfunctional in many autoimmune diseases, such as systemic lupus erythematosus (SLE), immune thrombocytopenia (ITP) and chronic graft-versus-host disease (cGVHD) [19, 29-32]. In this study, we found that the frequency of circulating IL-10-producing Bregs was significantly lower in DCM patients compared to healthy controls. Consistent with previous studies, IL-10-producing Bregs were mainly enriched in $\mathrm{CD} 24^{\mathrm{hi}} \mathrm{CD} 27^{+} \mathrm{B}$ cells. As $\mathrm{CD} 24^{\mathrm{hi}} \mathrm{CD} 27^{+} \mathrm{B}$ cells and $\mathrm{CD} 24^{\mathrm{hi}} \mathrm{CD} 38^{\mathrm{hi}} \mathrm{B}$ cells were both reported to exhibit regulatory functions in human autoimmune diseases [20], we detected their proportions and IL-10 expression in healthy controls and DCM patients. Although the proportions of both subsets were comparable between the 2 groups, the IL-10 production of $\mathrm{CD} 24^{\text {hi }} \mathrm{CD} 27^{+} \mathrm{B}$ cells from DCM patients was decreased. Consistent with this finding, CD24 $4^{\mathrm{hi}} \mathrm{CD} 27^{+} \mathrm{B}$ cells showed compromised functions in DCM. In addition, to reveal the relationship of Bregs and cardiac function, we performed a correlation analysis. Our results showed that the frequency of IL-10-producing Bregs and the suppressive function of $\mathrm{CD} 24^{\mathrm{hi}} \mathrm{CD} 27^{+} \mathrm{B}$ cells was positively correlated with the LVEF and negatively correlated with NT-proBNP of DCM patients. Our data are the first to report a lower proportion and impaired function of Bregs in DCM patients.

IL-10 remains the best phenotypic marker for human Bregs. B cells from freshly collected PBMCs express little IL-10 and after stimulation with PMA, ionomycin and brefeldin A for $5 \mathrm{~h}$, the frequency of IL-10 in B cells increases approximately $0.6 \%$ [20]. We detected the IL-10 expression of PBMCs stimulated through this method and consistent with previous studies, healthy controls and patients showed minimal IL-10 expression $(0.7 \%$ and $0.9 \%)$ after a 5-h stimulation (data not shown). Furthermore, the difference between the 2 groups was not statistically significant. However, a study by Guo et al. demonstrated a different result. 30 healthy controls and 30 DCM patients were involved in their experiment, and they showed an increase in the frequency of IL-10-producing Bregs from DCM patients compared to healthy controls $(5.2 \% \pm 2.6 \%$ vs. $2.3 \% \pm 0.9 \%)$ [33], with a much higher proportion of 
IL-10-producing B cells compared with our results and previous studies. The discrepancy may be attributed to different patients and methods of stimulation between the two studies. The DCM patients and healthy controls included in their study were relatively younger. Additionally, whole blood was incubated for $5 \mathrm{~h}$ in their experiment while we used PBMCs instead.

The minimal IL-10 expression of freshly isolated blood B cells makes quantitative analysis between the 2 groups difficult. However, after in vitro stimulation for $48 \mathrm{~h}$, B cells can be further induced to express cytoplasmic IL-10 [20]. CD40L and CpG-ODN2006 are optimal inducers of IL-10 production. In healthy controls, the frequency of IL- $10^{+} \mathrm{B}$ cells was significantly increased to approximately $5 \%$ after culture in the presence of CD40 and CpGODN2006 for 2 days [20]. According to previous studies, IL-10 expression levels significantly changed in many autoimmune diseases, such as SLE, RA and MS, after a 48-h stimulation [20]. Thus, we further stimulated PBMCs through this method and found that fewer IL-10producing Bregs were detected in DCM patients. This finding suggested that the potential capacity of B cells to produce IL-10 was impaired in DCM patients compared to controls, which might partly contribute to the excessive activation of the immune response in DCM.

As with Bregs, there may be various distinct subsets of human Bregs. We focused on the two novel phenotypes, namely $\mathrm{CD} 24^{\mathrm{hi}} \mathrm{CD} 38^{\mathrm{hi}} \mathrm{B}$ cells and $\mathrm{CD} 24^{\mathrm{hi}} \mathrm{CD} 27^{+} \mathrm{B}$ cells, which were widely reported to have regulatory effects $[19,20,27,34]$. Consistent with previous studies, we found that Bregs were predominantly identified within the $\mathrm{CD} 24^{\mathrm{hi}} \mathrm{CD} 27^{+} \mathrm{B}$ cell subpopulation. Although there was no difference in the ratios of both subsets between the 2 groups, IL-10 expression was significantly lower in $\mathrm{CD} 24^{\mathrm{hi}} \mathrm{CD} 27^{+} \mathrm{B}$ cells from DCM patients. Given that IL-10 is the critical effector molecule of Bregs, we suggested that the suppressive functions of $\mathrm{CD} 24^{\mathrm{hi}} \mathrm{CD} 27^{+} \mathrm{B}$ cells were impaired in DCM. Thus, we further studied the suppressive functions of $\mathrm{CD} 24^{\text {hi }} \mathrm{CD} 27^{+} \mathrm{B}$ cells.

During the development of DCM, persistent and chronic autoimmune T cell responses to cardiac self-antigen and elevated pro-inflammatory cytokines mediate continual cardiac destruction [26, 35-38]. Previous studies have shown that Bregs exhibit their suppressive functions via IL-10, TGF- $\beta$ and cell to cell contact involving CD86 and CD80 in both mouse and humans $[19,39]$. Consistent with previous studies, we found that CD $24^{\text {hi }} \mathrm{CD} 27^{+} \mathrm{B}$ cells could suppress the cytokines production and proliferation of Tconv cells in healthy controls. However, the suppressive function of $\mathrm{CD} 24^{\mathrm{hi}} \mathrm{CD} 27^{+} \mathrm{B}$ cells in the TNF- $\alpha$ production of Tconv cells was impaired in DCM patients, which may be associated with their decreased expression of IL-10. The ability of CD $24^{\text {hi }} \mathrm{CD} 27^{+} \mathrm{B}$ cells to inhibit the proliferation and IFN- $\gamma$ production of Tconv was not compromised in DCM patients, which suggested that other mechanisms besides IL-10 might participate in the processes.

Tregs are decreased and have impaired functionality in DCM [26, 40]. Additionally, cardiac-specific auto-antibodies that have been reported in DCM patients showed a pathogenic role in cardiac dilatation and dysfunction. Tregs could directly suppress B cell immunoglobulin production independent of T helper cells [41]. Bregs function by skewing $\mathrm{T}$ cell differentiation toward a regulatory phenotype in both mice $[42,43]$ and humans $[18,19$, 27]. $C D 24^{\text {hi }} \mathrm{CD} 38^{\text {hi }} \mathrm{B}$ cells maintain Treg differentiation in healthy individuals but not active RA patients. We first demonstrated that $\mathrm{CD} 24^{\text {hi }} \mathrm{CD} 27^{+} \mathrm{B}$ cells in healthy individuals could facilitate the differentiation of Tregs while they failed to convert Tconv cells to Tregs in DCM patients. This finding suggested that defective IL-10 expression of $\mathrm{CD} 24^{\text {hi }} \mathrm{CD} 27^{+} \mathrm{B}$ cells may be associated with the lower levels of Tregs found in DCM patients. Thus, the decreased function of $\mathrm{CD} 24^{\mathrm{hi}} \mathrm{CD} 27^{+} \mathrm{B}$ cells could have a significant impact on the pathogenic process of DCM.

\section{Conclusion}

This research illustrated a decreased frequency of circulating IL-10-producing Bregs in DCM patients. Moreover, IL-10 production was specifically decreased in CD $24^{\text {hi }} \mathrm{CD} 27^{+} \mathrm{B}$ cells. 
Impaired suppressive function of $\mathrm{CD} 24^{\text {hi }} \mathrm{CD} 27^{+} \mathrm{B}$ cells might be responsible for the activation of systemic immune inflammation during DCM pathogenesis. Our data provide a potential role for Bregs in the development of DCM.

\section{Abbreviations}

Bregs (regulatory B cells); DCM (dilated cardiomyopathy); LVEF (left ventricular ejection fraction); LVDD (left ventricular diastolic diameter); NT-proBNP (N-terminal B-type natriuretic peptide); Tregs (regulatory T cells); EAE (experimental autoimmune encephalomyelitis); CIA (collagen-induced arthritis); SLE (systemic lupus erythematosus); ITP (immune thrombocytopenia); cGVHD (chronic graft-versus-host disease); WHO (World Healthy Organization); NHYA (New York Heart Association); ACEI (angiotensin-converting enzyme inhibitor); ARB (angiotensin receptor blocker); PBMCs (peripheral blood monocular cells); mAb (monoclonal antibodies); CS (fetal calf serum); HEPES (4-(2-hydroxyethyl)-1piperazineethanesulfonic acid); FACS (fluorescence activated cell sorting); ELISA (enzymelinked immuno sorbent assay); TGF (transforming growth factor); TNF (tumor necrosis factor); PMA (phorbol-12-myristate-13-acetate); TH (T helper); SEM (standard error of mean).

\section{Acknowledgements}

The authors thank all of the patients and controls who participated in this study.

This work was supported by grants from the National Natural Science Foundation of China [No. 81525003, 81720108005, 91639301 to X.C.; No. 81400364, 81770503 to N.X.; No. 81670361 to T.T.T.; No. 81500186 to S.F.N.].

\section{Disclosure Statement}

No conflict of interests exists.

\section{References}

1 Jefferies JL, Towbin JA: Dilated cardiomyopathy. Lancet 2010;375:752-762.

-2 Maron BJ, Towbin JA, Thiene G, Antzelevitch C, Corrado D, Arnett D, Moss AJ, Seidman CE, Young JB, American Heart A, Council on Clinical Cardiology HF, Transplantation C, Quality of C, Outcomes R, Functional G, Translational Biology Interdisciplinary Working G, Council on E, Prevention: Contemporary definitions and classification of the cardiomyopathies: an American Heart Association Scientific Statement from the Council on Clinical Cardiology, Heart Failure and Transplantation Committee; Quality of Care and Outcomes Research and Functional Genomics and Translational Biology Interdisciplinary Working Groups; and Council on Epidemiology and Prevention. Circulation 2006;113:1807-1816.

-3 Heymans S, Hirsch E, Anker SD, Aukrust P, Balligand JL, Cohen-Tervaert JW, Drexler H, Filippatos G, Felix SB, Gullestad L, Hilfiker-Kleiner D, Janssens S, Latini R, Neubauer G, Paulus WJ, Pieske B, Ponikowski P, Schroen B, Schultheiss HP, Tschope C, Van Bilsen M, Zannad F, McMurray J, Shah AM: Inflammation as a therapeutic target in heart failure? A scientific statement from the Translational Research Committee of the Heart Failure Association of the European Society of Cardiology. Eur J Heart Fail 2009;11:119-129.

4 Cihakova D, Rose NR: Pathogenesis of myocarditis and dilated cardiomyopathy. Adv Immunol 2008;99:95114.

5 Yndestad A, Holm AM, Muller F, Simonsen S, Froland SS, Gullestad L, Aukrust P: Enhanced expression of inflammatory cytokines and activation markers in T-cells from patients with chronic heart failure. Cardiovasc Res 2003;60:141-146. 


\section{Cellular Physiology Cell Physiol Biochem 2018;46:23-35 \\ \begin{tabular}{l|l} 
and Biochemistry Published online: March 23, 2018 & $\begin{array}{l}\text { C) } 2018 \text { The Author(s). Published by S. Karger AG, Basel } \\
\text { www.karger.com/cpb }\end{array}$ \\
\hline
\end{tabular}}

Jiao et al.: Regulatory B Cells in Dilated Cardiomyopathy

-6 Ueno A, Murasaki K, Hagiwara N, Kasanuki H: Increases in circulating T lymphocytes expressing HLA-DR and CD40 ligand in patients with dilated cardiomyopathy. Heart Vessels 2007;22:316-321.

7 Okazaki T, Honjo T: Pathogenic roles of cardiac autoantibodies in dilated cardiomyopathy. Trends Mol Med 2005;11:322-326.

8 Jane-wit D, Altuntas CZ, Johnson JM, Yong S, Wickley PJ, Clark P, Wang Q, Popovic ZB, Penn MS, Damron DS, Perez DM, Tuohy VK: Beta 1-adrenergic receptor autoantibodies mediate dilated cardiomyopathy by agonistically inducing cardiomyocyte apoptosis. Circulation 2007;116:399-410.

-9 Noutsias M, Rohde M, Goldner K, Block A, Blunert K, Hemaidan L, Hummel M, Blohm JH, Lassner D, Kuhl U, Schultheiss HP, Volk HD, Kotsch K: Expression of functional T-cell markers and T-cell receptor Vbeta repertoire in endomyocardial biopsies from patients presenting with acute myocarditis and dilated cardiomyopathy. Eur J Heart Fail 2011;13:611-618.

10 Kubota T, McTiernan CF, Frye CS, Slawson SE, Lemster BH, Koretsky AP, Demetris AJ, Feldman AM: Dilated cardiomyopathy in transgenic mice with cardiac-specific overexpression of tumor necrosis factor-alpha. Circ Res 1997;81:627-635.

11 Tang Z, McGowan BS, Huber SA, McTiernan CF, Addya S, Surrey S, Kubota T, Fortina P, Higuchi Y, Diamond MA, Wyre DS, Feldman AM: Gene expression profiling during the transition to failure in TNF-alpha over-expressing mice demonstrates the development of autoimmune myocarditis. J Mol Cell Cardiol 2004;36:515-530.

12 Magnusson Y, Wallukat G, Waagstein F, Hjalmarson A, Hoebeke J: Autoimmunity in idiopathic dilated cardiomyopathy. Characterization of antibodies against the beta 1-adrenoceptor with positive chronotropic effect. Circulation 1994;89:2760-2767.

13 Matsui S, Fu ML, Katsuda S, Hayase M, Yamaguchi N, Teraoka K, Kurihara T, Takekoshi N, Murakami E, Hoebeke J, Hjalmarson A: Peptides derived from cardiovascular G-protein-coupled receptors induce morphological cardiomyopathic changes in immunized rabbits. J Mol Cell Cardiol 1997;29:641-655.

-14 Matsushita T, Yanaba K, Bouaziz JD, Fujimoto M, Tedder TF: Regulatory B cells inhibit EAE initiation in mice while other B cells promote disease progression. J Clin Invest 2008;118:3420-3430.

15 Hussain S, Delovitch TL: Intravenous transfusion of BCR-activated B cells protects NOD mice from type 1 diabetes in an IL-10-dependent manner. J Immunol 2007;179:7225-7232.

16 Mauri C, Gray D, Mushtaq N, Londei M: Prevention of arthritis by interleukin 10-producing B cells. J Exp Med 2003;197:489-501.

17 Rosser EC, Mauri C: Regulatory B cells: origin, phenotype, and function. Immunity 2015;42:607-612.

18 Mauri C, Bosma A: Immune regulatory function of B cells. Annu Rev Immunol 2012;30:221-241.

19 Blair PA, Norena LY, Flores-Borja F, Rawlings DJ, Isenberg DA, Ehrenstein MR, Mauri C: CD19(+)CD24(hi) CD38(hi) B cells exhibit regulatory capacity in healthy individuals but are functionally impaired in systemic Lupus Erythematosus patients. Immunity 2010;32:129-140.

20 Iwata Y, Matsushita T, Horikawa M, Dilillo DJ, Yanaba K, Venturi GM, Szabolcs PM, Bernstein SH, Magro CM, Williams AD, Hall RP, St Clair EW, Tedder TF: Characterization of a rare IL-10-competent B-cell subset in humans that parallels mouse regulatory B10 cells. Blood 2011;117:530-541.

21 Richardson P, McKenna W, Bristow M, Maisch B, Mautner B, O’Connell J, Olsen E, Thiene G, Goodwin J, Gyarfas I, Martin I, Nordet P: Report of the 1995 World Health Organization/International Society and Federation of Cardiology Task Force on the Definition and Classification of cardiomyopathies. Circulation 1996;93:841-842.

-22 Agematsu K, Hokibara S, Nagumo H, Komiyama A: CD27: a memory B-cell marker. Immunol Today 2000;21:204-206.

23 Sanz I, Wei C, Lee FE, Anolik J: Phenotypic and functional heterogeneity of human memory B cells. Semin Immunol 2008;20:67-82.

24 Palanichamy A, Barnard J, Zheng B, Owen T, Quach T, Wei C, Looney RJ, Sanz I, Anolik JH: Novel human transitional B cell populations revealed by B cell depletion therapy. J Immunol 2009;182:5982-5993.

25 Plebani A, Lougaris V, Soresina A, Meini A, Zunino F, Losi CG, Gatta R, Cattaneo G, Nespoli L, Marinoni M, Capolunghi F, Vivarelli M, Quinti I, Carsetti R: A novel immunodeficiency characterized by the exclusive presence of transitional B cells unresponsive to CpG. Immunology 2007;121:183-188.

-26 Zhu ZF, Tang TT, Dong WY, Li YY, Xia N, Zhang WC, Zhou SF, Yuan J, Liao MY, Li JJ, Jiao J, Nie SF, Wang Q, Tu X, Xu CQ Liao YH, Shi GP, Cheng X: Defective circulating CD4+LAP+ regulatory T cells in patients with dilated cardiomyopathy. J Leukoc Biol 2015;97:797-805. 


\section{Cellular Physiology Cell Physiol Biochem 2018;46:23-35

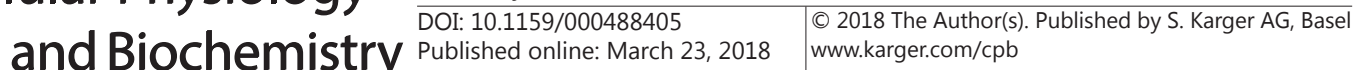 \\ Jiao et al.: Regulatory B Cells in Dilated Cardiomyopathy}

27 Flores-Borja F, Bosma A, Ng D, Reddy V, Ehrenstein MR, Isenberg DA, Mauri C: CD19+CD24hiCD38hi B cells maintain regulatory T cells while limiting TH1 and TH17 differentiation. Sci Transl Med 2013;5:173ra123.

28 Mizoguchi A, Bhan AK: A case for regulatory B cells. J Immunol 2006;176:705-710.

29 Li X, Zhong H, Bao W, Boulad N, Evangelista J, Haider MA, Bussel J, Yazdanbakhsh K: Defective regulatory B-cell compartment in patients with immune thrombocytopenia. Blood 2012;120:3318-3325.

-30 Khoder A, Sarvaria A, Alsuliman A, Chew C, Sekine T, Cooper N, Mielke S, de Lavallade H, Muftuoglu M, Fernandez Curbelo I, Liu E, Muraro PA, Alousi A, Stringaris K, Parmar S, Shah N, Shaim H, Yvon E, Molldrem J, Rouce R, Champlin R, McNiece I, Mauri C, Shpall EJ, Rezvani K: Regulatory B cells are enriched within the IgM memory and transitional subsets in healthy donors but are deficient in chronic GVHD. Blood 2014;124:2034-2045.

-31 Zha B, Wang L, Liu X, Liu J, Chen Z, Xu J, Sheng L, Li Y, Chu Y: Decrease in proportion of CD19+ CD24(hi) CD27+ B cells and impairment of their suppressive function in Graves' disease. PLoS One 2012;7:e49835.

-32 Kim J, Lee HJ, Yoo IS, Kang SW, Lee JH: Regulatory B cells are inversely associated with disease activity in rheumatoid arthritis. Yonsei Med J 2014;55:1354-1358.

33 Guo Y, Cen Z, Wei B, Wu W, Zhou Q: Increased circulating interleukin 10-secreting B cells in patients with dilated cardiomyopathy. Int J Clin Exp Pathol 2015;8:8107-8114.

34 Bosma A, Abdel-Gadir A, Isenberg DA, Jury EC, Mauri C: Lipid-antigen presentation by CD1d (+) B cells is essential for the maintenance of invariant natural killer T cells. Immunity 2012;36:477-490.

-35 Guedes PM, Gutierrez FR, Silva GK, Dellalibera-Joviliano R, Rodrigues GJ, Bendhack LM, Rassi A, Jr., Rassi A, Schmidt A, Maciel BC, Marin Neto JA, Silva JS: Deficient regulatory T cell activity and low frequency of IL-17producing T cells correlate with the extent of cardiomyopathy in human Chagas' disease. PLoS Negl Trop Dis 2012;6:e1630.

-36 Jahns R, Boivin V, Hein L, Triebel S, Angermann CE, Ertl G, Lohse MJ: Direct evidence for a beta 1-adrenergic receptor-directed autoimmune attack as a cause of idiopathic dilated cardiomyopathy. J Clin Invest 2004;113:1419-1429.

-37 Aukrust P, Yndestad A, Damas JK, Gullestad L: Inflammation and chronic heart failure-potential therapeutic role of intravenous immunoglobulin. Autoimmun Rev 2004;3:221-227.

38 Wei L: Immunological aspect of cardiac remodeling: T lymphocyte subsets in inflammation-mediated cardiac fibrosis. Exp Mol Pathol 2011;90:74-78.

39 Mann MK, Maresz K, Shriver LP, Tan Y, Dittel BN: B cell regulation of CD4+CD25+ T regulatory cells and IL-10 via B7 is essential for recovery from experimental autoimmune encephalomyelitis. J Immunol 2007;178:3447-3456.

40 Li J, Wang L, Wang S, Zhu H, Ye P, Xie A, Shen B, Liu C, Guo C, Fu Q Zhang K, Xia J: The Treg/Th17 imbalance in patients with idiopathic dilated cardiomyopathy. Scand J Immunol 2010;71:298-303.

-41 Lim HW, Hillsamer P, Banham AH, Kim CH: Cutting edge: direct suppression of B cells by CD4+ CD25+ regulatory T cells. J Immunol 2005;175:4180-4183.

-42 Carter NA, Vasconcellos R, Rosser EC, Tulone C, Munoz-Suano A, Kamanaka M, Ehrenstein MR, Flavell RA, Mauri C: Mice lacking endogenous IL-10-producing regulatory B cells develop exacerbated disease and present with an increased frequency of Th1/Th17 but a decrease in regulatory T cells. J Immunol 2011;186:5569-5579.

43 Bankoti R, Gupta K, Levchenko A, Stager S: Marginal zone B cells regulate antigen-specific T cell responses during infection. J Immunol 2012;188:3961-3971. 